\title{
Analysis of Corrosion Degradation of TiCrN Coatings Subjected to High Temperatures
}

\author{
W. Aperador ${ }^{1}$, A. Delgado ${ }^{1}$, J. C. Caicedo ${ }^{2}$ \\ ${ }^{1}$ School of Engineering, Universidad Militar Nueva Granada, Bogotá-Colombia \\ ${ }^{2}$ Tribology Polymers, Powder Metallurgy and Processing of Solid Recycled Research Group \\ Universidad del Valle, Cali - Colombia \\ *E-mail: g.ing.materiales@gmail.com
}

doi: $10.20964 / 2017.05 .33$

Received: 8 February 2017 / Accepted: 16 March 2017 / Published: 12 April 2017

\begin{abstract}
In order to provide a procedure for corrosive problems in industrial devices, Thin films of titanium chromium nitride were deposits onto 316LVM steel substrates using a multi target magnetron sputtering system with radio frequency, sources from Titanium and Chromium sputtering targets of high purity $(99.99 \%)$. The corrosion analysis was performed by electrochemical impedance spectroscopy and Tafel polarization curves, where it is determined that the coatings are adhered to the substrate and evaluated in a solid solution at different temperatures ranging from $600^{\circ} \mathrm{C}$ to $700^{\circ} \mathrm{C}$, The substrate and coatings morphology were performed by scanning electron microscopy (SEM) being a different topography for each one of the evaluated temperatures, this due to the corrosive effect and the high temperatures that generated processes of obtaining oxides as also of carbides due to the corrosive phenomenon of the coatings, the effect of the corrosive phenomenon was also determined by the change in the crystal structure as the temperature increases, XRD analysis were done on thin films samples, the change of microstructure changes due to defects such as porosities and cracks generates easy access connections for solid solution ions, which facilitates the entry into the coating-like material in contact with the corrosive salts.
\end{abstract}

Keywords: Coatings, corrosion, high temperatures, corrosive salts, magnetron sputtering.

\section{$\underline{\text { FULL TEXT }}$}

(C) 2017 The Authors. Published by ESG (www.electrochemsci.org). This article is an open access article distributed under the terms and conditions of the Creative Commons Attribution license (http://creativecommons.org/licenses/by/4.0/). 